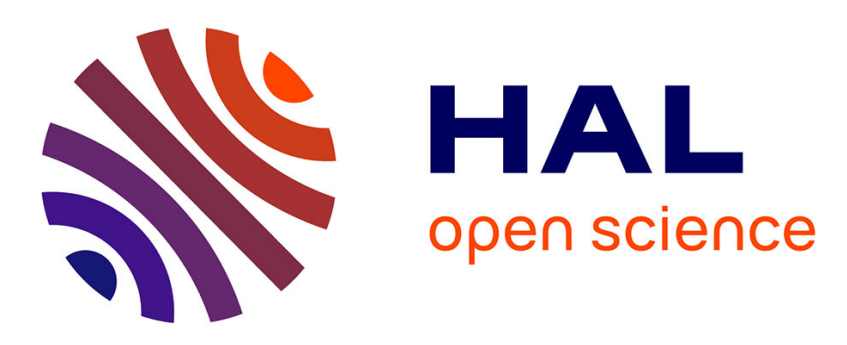

\title{
In situ infrared absorption spectroscopy of dusty plasmas
}

G. M. W. Kroesen, J. H. W. G. den Boer, L. Boufendi, F. Vivet, M. Khouli, A. Bouchoule, F. J. de Hoog

\section{- To cite this version:}

G. M. W. Kroesen, J. H. W. G. den Boer, L. Boufendi, F. Vivet, M. Khouli, et al.. In situ infrared absorption spectroscopy of dusty plasmas. Journal of Vacuum Science \& Technology A, 1996, 14 (2), pp.546-549. 10.1116/1.580142 . hal-02111970

\section{HAL Id: hal-02111970 https://hal.science/hal-02111970}

Submitted on 26 Apr 2019

HAL is a multi-disciplinary open access archive for the deposit and dissemination of scientific research documents, whether they are published or not. The documents may come from teaching and research institutions in France or abroad, or from public or private research centers.
L'archive ouverte pluridisciplinaire HAL, est destinée au dépôt et à la diffusion de documents scientifiques de niveau recherche, publiés ou non, émanant des établissements d'enseignement et de recherche français ou étrangers, des laboratoires publics ou privés. 


\title{
In situ infrared absorption spectroscopy of dusty plasmas
}

\author{
Kroesen, G.M.W.; Boer, den, J.H.W.G.; Boufendi, L.; Vivet, F.; Khouli, M.; Bouchoule, A.; de
} Hoog, F.J.

Published in:

Journal of Vacuum Science and Technology. A: Vacuum, Surfaces, and Films

DOI:

$10.1116 / 1.580142$

Published: 01/01/1996

Document Version

Publisher's PDF, also known as Version of Record (includes final page, issue and volume numbers)

Please check the document version of this publication:

- A submitted manuscript is the author's version of the article upon submission and before peer-review. There can be important differences between the submitted version and the official published version of record. People interested in the research are advised to contact the author for the final version of the publication, or visit the DOI to the publisher's website.

- The final author version and the galley proof are versions of the publication after peer review.

- The final published version features the final layout of the paper including the volume, issue and page numbers.

Link to publication

Citation for published version (APA):

Kroesen, G. M. W., Boer, den, J. H. W. G., Boufendi, L., Vivet, F., Khouli, M., Bouchoule, A., \& Hoog, de, F. J. (1996). In situ infrared absorption spectroscopy of dusty plasmas. Journal of Vacuum Science and Technology. A: Vacuum, Surfaces, and Films, 14(2), 546-549. DOI: 10.1116/1.580142

\section{General rights}

Copyright and moral rights for the publications made accessible in the public portal are retained by the authors and/or other copyright owners and it is a condition of accessing publications that users recognise and abide by the legal requirements associated with these rights.

- Users may download and print one copy of any publication from the public portal for the purpose of private study or research.

- You may not further distribute the material or use it for any profit-making activity or commercial gain

- You may freely distribute the URL identifying the publication in the public portal ?

Take down policy

If you believe that this document breaches copyright please contact us providing details, and we will remove access to the work immediately and investigate your claim. 


\title{
In situ infrared absorption spectroscopy of dusty plasmas
}

\author{
G. M. W. Kroesen and J. H. W. G. den Boer \\ Eindhoven University of Technology, 5600 MB Eindhoven, The Netherlands \\ L. Boufendi, F. Vivet, M. Khouli, and A. Bouchoule \\ GREMI, Université d'Orléans, 45067 Orléans Cedex 02, France \\ F. J. de Hoog \\ Eindhoven University of Technology, 5600 MB Eindhoven, The Netherlands
}

(Received 4 October 1995; accepted 13 December 1995)

\begin{abstract}
In situ, time-resolved Fourier transform infrared spectroscopy was used to study particulate formation in rf discharges in mixtures of silane, argon, and nitrogen. The spectra were taken at a maximum rate of $20 \mathrm{~Hz}$. The discharge conditions were chosen such that previous calibrations of the time evolutions of particle size and density could be used. The measurements indicate that the onset of the solid-state vibrational absorptions of the $\mathrm{SiH}$ and $\mathrm{SiH}_{2}$ bands only takes place after the nucleation and coagulation phase have finished; it coincides with the previously predicted start of the deposition of amorphous hydrogenated silicon on the particles. The dissociation of the silane feed gas is found to be in the range of $30 \%$, and its time development suggests that also the large-scale dissociation of silane only starts after the coagulation phase. This is in agreement with previously observed trends for the electron temperature. If silicon partilces are grown in the plasma, and the silane flow is stopped, the Si particles stay trapped in the glow. The infrared measurements, however, show that they almost completely oxidize: the $\mathrm{SiH} / \mathrm{SiH}_{2}$ vibrations disappear and a strong $\mathrm{SiO}$ vibration appears. If nitrogen gas is allowed into the plasma, the $\mathrm{SiO}$ vibration is replaced by a SiN vibration. (C) 1996 American Vacuum Society.
\end{abstract}

\section{INTRODUCTION}

A great effort has been made lately to clarify the formation mechanism of macroscopic particulates in a rf plasma because of their destructive role in surface processing like deposition, etching, or sputtering. More recently, interest in the possibility to generate particles with a well defined size distribution and controllable chemical composition has emerged. Examples of application of those plasma generated particles can be found within the field of electronics (crystalline silicon particles), catalysis and ceramics (particles with a core of silicon nitride, oxide, or carbide covered with a metal or metal oxide film), and lighting (covering fluorescent powders with a protective coating). A better understanding of the particle formation and growth process will make it possible to enhance process and product control.

In order to elucidate the actual formation process in a given gas mixture and configuration it is necessary to monitor the particulate composition during the growth process. If the clusters contain infrared active bonds, this analysis can be performed using Fourier transform infrared (FTIR) absorption spectroscopy. In this work we apply this technique to particulates formed in rf discharges containing argon, silane, methane, and nitrogen.

\section{EXPERIMENT}

The experiments were performed in a $13.56 \mathrm{MHz}$ capacitively coupled plasma in a planar 12-cm-diam parallel plate configuration. The distance between the aluminum electrodes is $5 \mathrm{~cm}$. The input power can be varied between 0 and 100 W. The gas pressure and flow can be varied independently from 5 to $500 \mathrm{mTorr}$ and from 0 to $10 \mathrm{sccm}$, respectively, using a throttle valve in the pumping line. The gases are fed through MKS mass flow controllers and introduced homogeneously through a shower head in the rf electrode. The opposite, grounded electrode consists of a grid to allow the particles to be removed from the "plasma box" with the gas flow. In order to obtain a good base pressure an oil diffusion pump is used. During plasma operation just a rotary pump is applied. The discharge and the growth of silicon particles in it are well characterized. For certain parameter settings, the time evolution of the particle size, the particle density, and the electron density and temperature have been determined previously (see Fig. 1). ${ }^{1,2}$ In short, one can distinguish three phases: (1) nucleation: almost immediately after plasma ignition the particle density is very high $\left(10^{9} \mathrm{~cm}^{-3}\right)$ and the average size is very small (a few $\mathrm{nm}$ ); (2) coagulation: in the next $5 \mathrm{~s}$ these precursors coagulate to form larger particles (up to $50 \mathrm{~nm}$ ), meanwhile, the density decreases (down to $10^{8} \mathrm{~cm}^{-3}$ ); (3) a-Si:H deposition: after $5 \mathrm{~s}$ there is a steady growth of the particles, presumably caused by the deposition of amorphous hydrogenated silicon $(a-\mathrm{Si}: \mathrm{H})$, without the density changing much. In this work we have used those calibrated settings (120 mTorr total pressure, 4 mass percent of silane in argon, $3 \mathrm{~W}$ of rf power).

For the infrared measurements $\mathrm{NaCl}$ windows have been mounted. The spectra have been collected using a Bruker IFS-66 Fourier interferometer with a glowbar as a continuous light source. The FTIR is basically a Michelson interferometer, supplied with a fixed and a moving mirror. This provides a time varying interference signal for all wavelengths. The parallel beam exiting the spectrometer is directed 


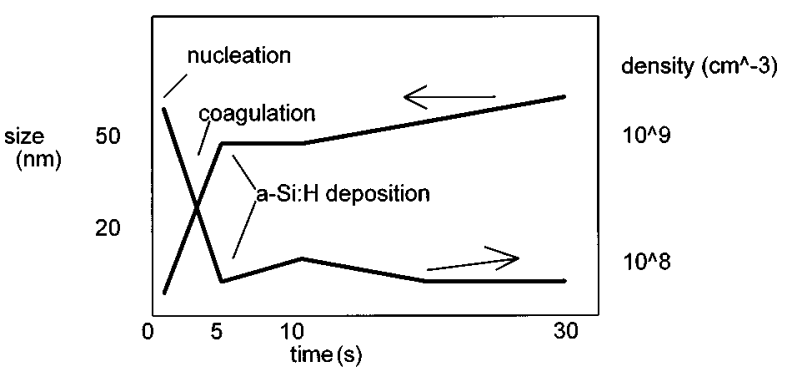

FIG. 1. The evolutions of size and density of particulates growing at room temperature in an argon/silane discharge. The pressure is 120 mTorr, the silane volume fraction is $4 \%$, the rf power into the 12 -cm-diam electrode is 3 W (adapted from Ref. 1).

through the plasma (single pass, see Fig. 2). Then it is focused with an off-axis paraboloid mirror onto a mercurycadmium-telluride (MCT) detector. A Fourier transform of the detector signal yields a spectrum in the wave number range of $600-5000 \mathrm{~cm}^{-1}$ with a spectral resolution of $4 \mathrm{~cm}^{-1}$. In order to avoid too strong an appearance of the absorption bands of water and $\mathrm{CO}_{2}$, that are always present in the ambient, the infrared (IR) light beam was enclosed in plastic tubing that was continuously flushed with nitrogen gas. Nevertheless, sometimes the (clearly recognizable) absorptions of $\mathrm{H}_{2} \mathrm{O}$ and $\mathrm{CO}_{2}$ could not be completely avoided. In order to avoid arcing of the discharge in the slits that were made in the plasma box to allow access of the IR beam, in some cases (especially at high power) those slits were covered with a grid.

Since the growth of the particles is very reproducible, the following measurement sequence was performed. First, the gas flows and pressure are set and allowed to stabilize. Then the discharge is ignited, and IR absorption spectra are taken at a rate of $20 \mathrm{~Hz}$ for several seconds. The first spectrum serves as reference spectrum and is taken before the discharge is ignited. The rf power is switched on and off by a digital port of the FTIR in order to synchronize the experiment. After the rf power is switched off, a few seconds are taken to allow the grown particles to be blown out of the plasma box. Then the rf power is switched on again, and the sequence is repeated. The series of IR spectra are co-added each time. By repeating this sequence a few thousand times,

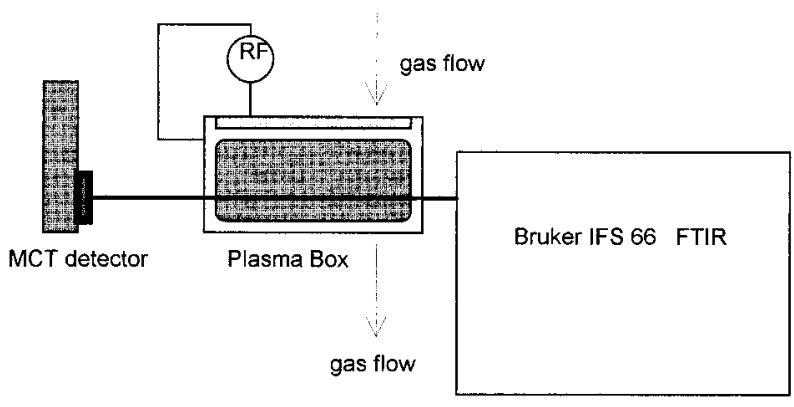

FIG. 2. Outline of the experimental setup used for the in situ IR absorption spectroscopy experiments.

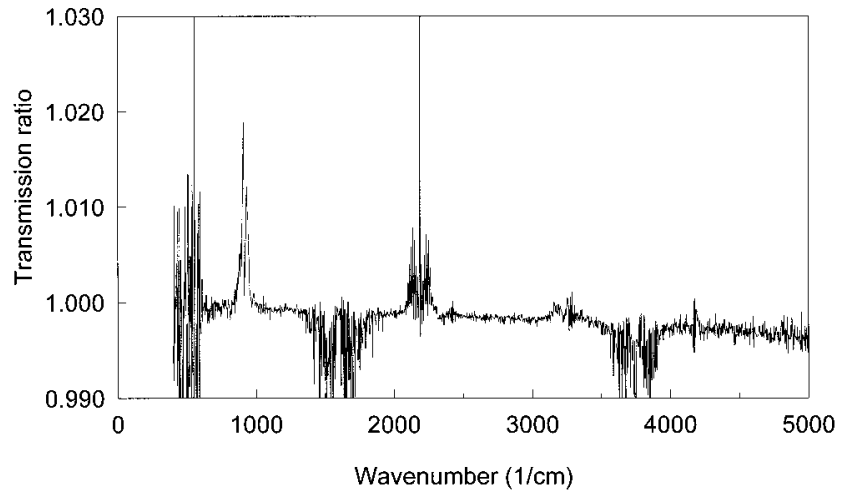

FIG. 3. The absorption spectrum of silane gas without plasma.

the signal to noise ratio is brought up to a level that allows absorptions of $10^{-3}$ to be detected. The experiments typically take a total time of a few hours and result in one sequence of averaged IR spectra. Since the spectra are taken at intervals of $50 \mathrm{~ms}$, the IR absorption by molecules as well as particles in the plasma can be monitored with the same time resolution.

\section{RESULTS AND DISCUSSION}

First, a note concerning the labels of all vertical axes of displayed spectra. They all read "transmission ratio" because they are obtained by dividing two (transmission) spectra as directly measured by the FTIR. For each figure it is then indicated separately in the text how to interpret the direction (upwards or downwards) of the various peak structures (visible).

Figure 3 shows the absorption spectrum of pure silane gas. It was obtained by dividing the spectrum with silane gas (measured last) on the spectrum without silane gas (measured first). Clearly recognizable are the two $\mathrm{SiH}_{4}$ bands around 900 and around $2100 \mathrm{~cm}^{-1}$. The intensity of the $Q$-branch of $\mathrm{SiH}_{4}$ at $2187 \mathrm{~cm}^{-1}$ can be used as a measure for the concentration of silane gas. An absorption of 3\% of this peak corresponds to the partial pressure of silane without plasma (4.8 mTorr). The strong bands around 1500 and 3700

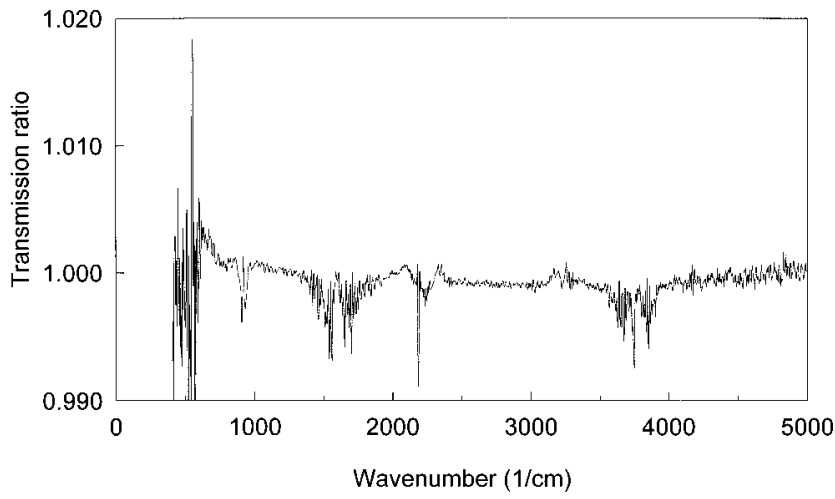

FIG. 4. The absorption spectrum of a silane plasma $(5 \mathrm{~min})$ containing powders. 


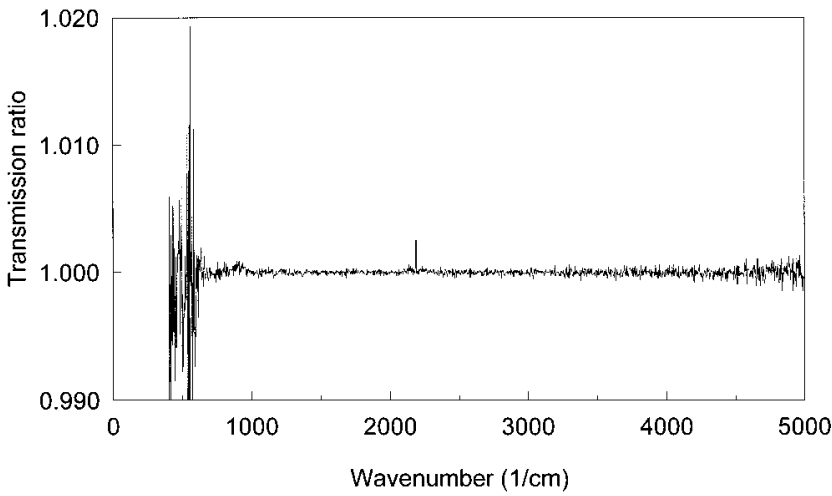

FIG. 5. The absorption spectrum of a silane plasma immediately after plasma ignition.

$\mathrm{cm}^{-1}$ are caused by water. Apparently the amount of water in the optical system or in the plasma chamber has decreased slightly between the two measurements. In Fig. 4 the absorption spectrum of a silane discharge $(5 \mathrm{~min})$ with powders is given. This spectrum is obtained by dividing the spectrum with plasma (and powders) on the spectrum without plasma (but with the silane gas). Bands that point upwards indicate an increase in absorption; bands that point downwards indicate a decrease of absorption upon plasma ignition. Apart from the already known silane absorptions (which now point downwards with about $1 \%$ absorption in the $Q$-band, indicating a decrease in density when the plasma is switched on, corresponding to a dissociation degree of $30 \%$ ), one can recognize the solid-state $\mathrm{Si}-\mathrm{H}$ vibration around 2010 and $\mathrm{Si}-\mathrm{H}_{2}$ around $2110 \mathrm{~cm}^{-1}$, a band around $3000 \mathrm{~cm}^{-1}$ (maybe, $\mathrm{C}-\mathrm{H}$, could be carbon contamination coming from pump oil and incorporated in the particles), and a band around $650 \mathrm{~cm}^{-1}(\mathrm{Si}-\mathrm{H})$. The spectra of solid-state $\mathrm{SiH} / \mathrm{SiH}_{2}$ and gas phase $\mathrm{SiH}_{4}$ overlap partially.

When the spectra are taken time resolved (one spectrum each $2 \mathrm{~s}$, first spectrum without plasma, then each $2 \mathrm{~s}$ with plasma on; then the ratio of the spectrum without plasma and the spectra with plasma are calculated), the time evolution of the $\mathrm{SiH} / \mathrm{SiH}_{2}$ solid-state and $\mathrm{SiH}_{4}$ gas phase absorptions as a function of time can be obtained. Immediately after switch

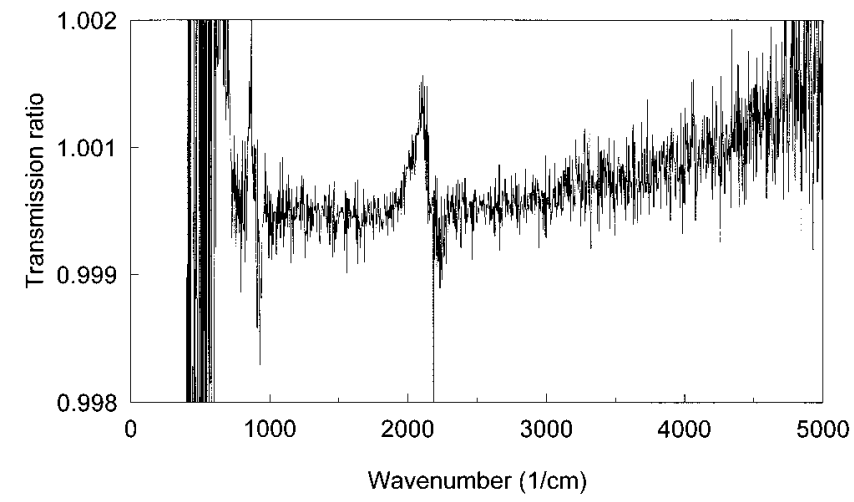

FIG. 6. The absorption spectrum of a silane plasma after $40 \mathrm{~s}$ of plasma operation.



FIG. 7. The spectrum of Fig. 6 with the (scaled) spectrum of silane gas (Fig. 3) substrated.

on (Fig. 5) no solid-state absorption and only a small change in the silane concentration are visible. After $40 \mathrm{~s}$ (Fig. 6) the $\mathrm{Si}-\mathrm{H}_{x}$ bands at 650 and $2010 / 2110 \mathrm{~cm}^{-1}$ become visible. Also one again sees the change in the $\mathrm{SiH}_{4}$ absorption. Furthermore, a continuous increase towards larger wave numbers (shorter wavelength) is observed. This is caused by Mie-Rayleigh scattering of the IR beam by the particles. In Fig. 7 the silane gas contribution in the spectrum of Fig. 5 is eliminated by subtracting the (scaled) silane spectrum (Fig. 3 ); now a clean $\mathrm{Si}-\mathrm{H} / \mathrm{Si}-\mathrm{H}_{2}$ solid-state vibrational band is visible. The deformations around 1500 and $3700 \mathrm{~cm}^{-1}$ in Fig. 7 are caused by the contributions of $\mathrm{H}_{2} \mathrm{O}$ (which is present in the optical path outside the plasma reactor) which are also visible in the used silane spectrum. In Figs. 8 and 9 the time evolution of the directly measured intensity at 2110 $\left(\mathrm{Si}-\mathrm{H}_{2}\right)$ and $2187 \mathrm{~cm}^{-1}$ (silane $Q$-branch absorption) is given. It has been verified that the displayed time dependencies are not caused by changes in the IR background signal or the scattered light by comparing the time dependencies with results obtained at frequencies that are close to but not in the $\mathrm{Si}-\mathrm{H}_{2}$ or the $\mathrm{SiH}_{4}$ absorption regions. The time evolution of the $2010 \mathrm{~cm}^{-1} \mathrm{SiH}$ vibration is similar to the one of $\mathrm{SiH}_{2}$ and is not displayed separately. For $2110 \mathrm{~cm}^{-1}$, a decrease of the measured intensity corresponds to an increase in $\mathrm{SiH}_{2}$ absorption. For $2187 \mathrm{~cm}^{-1}$ an increase of the mea-

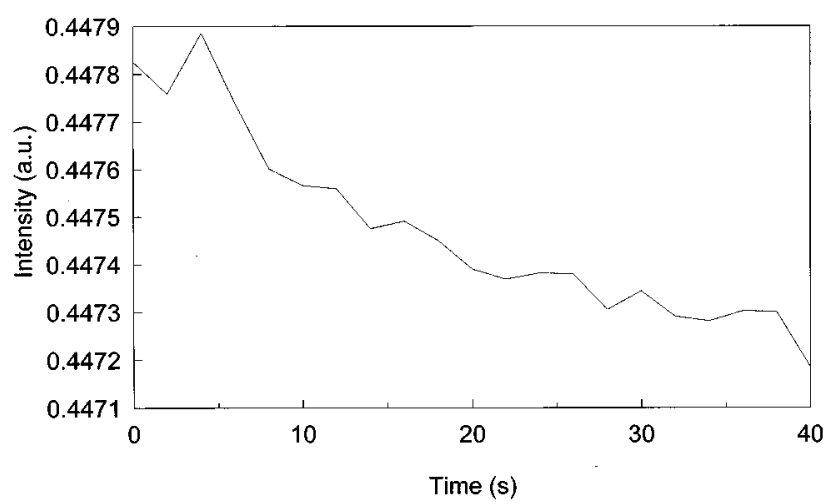

FIG. 8. Evolution of the measured intensity at the $\mathrm{SiH}_{2}$ solid-state absorption wave number $\left(2110 \mathrm{~cm}^{-1}\right)$ as a function of time after plasma ignition. 


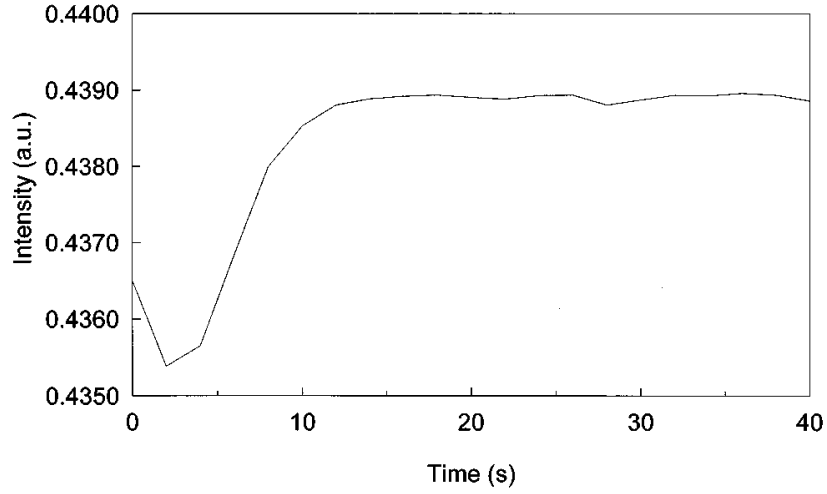

FIG. 9. The evolution of the measured intensity at the $\mathrm{SiH}_{4} Q$-branch absorption wave number $\left(2187 \mathrm{~cm}^{-1}\right)$ as a function of time after plasma ignition.

sured intensity corresponds to a decreased $\mathrm{SiH}_{4}$ absorption and hence to an increased $\mathrm{SiH}_{4}$ dissociation. One can see that the $\mathrm{Si}-\mathrm{H}_{2}$ solid-state absorption only appears after about $5 \mathrm{~s}$, and then increases rapidly to an equilibrium value. If one compares this to the time evolutions of particle size and density given in Fig. 1, one can conclude that the solid-state absorption of $\mathrm{SiH} / \mathrm{SiH}_{2}$ only sets in after the coagulation of the clusters into $50 \mathrm{~nm}$ particulates has finished. Apparently, before that point there is no amorphous silicon deposition on the particles. One can also argue that it may not be appropriate to speak about a "solid-state phase" for particles smaller than $50 \mathrm{~nm}$. Figure 9 indicates that the dissociation degree of silane only becomes substantial after $5 \mathrm{~s}$. This is consistent with previous observations using Langmuir probe techniques and emission spectroscopy, which indicate that the electron temperature and electron density also only show a substantial increase and decrease respectively at that point. $^{2}$

In Fig. 10 the spectrum of Si powders trapped in an argon plasma is shown. The powders were produced in a $5 \mathrm{~min}$ $\mathrm{Ar} / \mathrm{SiH}_{4}$ discharge, after which the silane flow was switched off. The powders remain trapped in the glow. The displayed spectrum is the ratio of the spectrum of the vacuum vessel filled with only argon and the spectrum of the trapped powders. If one looks closely, one can see that the $\mathrm{SiH} / \mathrm{SiH}_{2}$ band is reduced by a factor of 2 , and that a strong $\mathrm{Si}-\mathrm{O}_{x}$ band

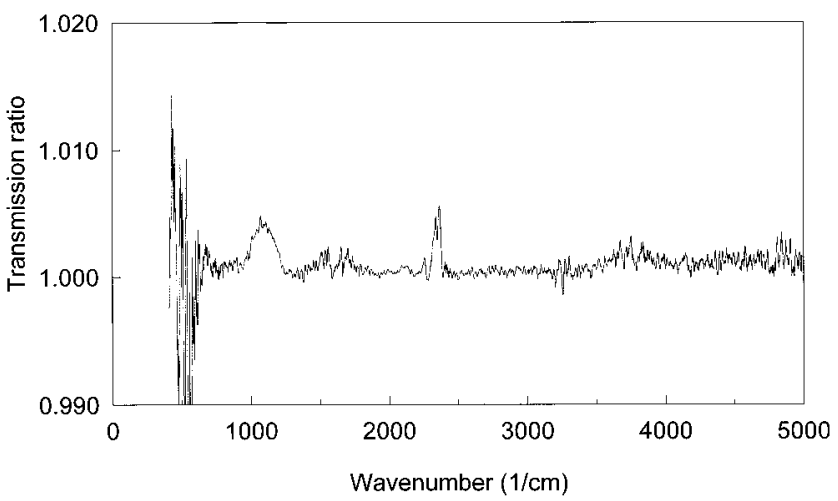

FIG. 10. The absorption spectrum of Si particles trapped in an argon discharge.

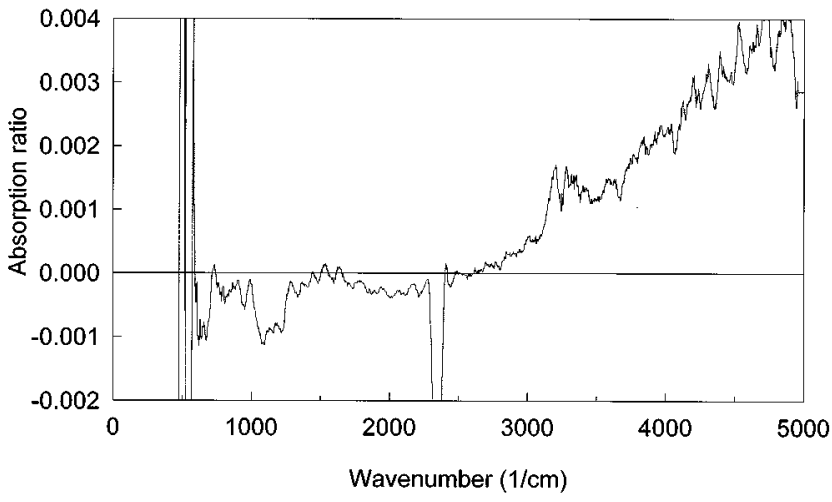

FIG. 11. The absorption spectrum difference which results from treating the particles trapped in argon (see Fig. 10) with a nitrogen discharge.

(1100-1200 $\mathrm{cm}^{-1}$ ) appears. Apparently, if they are trapped in argon, the powders rapidly oxidize by the impact of the small amount of residual water which is always present in a vacuum system. Figure 11 illustrates the difference of powders trapped in argon and the subsequent treatment by a nitrogen plasma. The spectrum was obtained by subtracting the spectrum after $\mathrm{N}_{2}$ treatment from the spectrum before $\mathrm{N}_{2}$ treatment. If peaks point downward, the corresponding absorption reduces, and if they point upwards, the corresponding absorption increases at nitrogen introduction. Disappearing or at least reducing are the $\mathrm{Si}-\mathrm{O}$ band at 1100$1200 \mathrm{~cm}^{-1}$ and the $\mathrm{Si}-\mathrm{H}$ bands at 650 and $2000-2100 \mathrm{~cm}^{-1}$. Appearing are a weak $\mathrm{Si}-\mathrm{N}$ band $\left(1400 \mathrm{~cm}^{-1}\right)$ and a Rayleigh scattering continuum $\left(3000-5000 \mathrm{~cm}^{-1}\right)$. This indicates that hydrogen and oxygen in the particles are replaced by nitrogen. The increase of the Mie-Rayleigh continuum points to either an increasing particle size (improbable) or a changing refractive index (more likely, $\mathrm{SiO}_{2}$ has a refractive index of about 1.46, $\mathrm{Si}_{3} \mathrm{~N}_{4}$ of 2.0). Also an extra band around $3000 \mathrm{~cm}^{-1}$ appears (probably $\mathrm{CH}$ from pump oil contamination).

\section{CONCLUSIONS}

In situ infrared absorption spectroscopy during the growth of particulates in discharges of silane/argon mixtures provides a wealth of information. Even at the applied low discharge powers $(3 \mathrm{~W})$ the silane dissociation is large $(30 \%)$. The solid-state absorptions of $\mathrm{SiH}$ and $\mathrm{SiH}_{2}$ only appear after the coagulation phase. Silicon powders trapped in an argon plasma rapidly oxidize. After nitrogen introduction in the discharge, the hydrogen and oxygen atoms which are present in the trapped powders are exchanged for nitrogen.

\section{ACKNOWLEDGMENTS}

This research has been funded partially by the European Commission under Contract No. BRE-CT94-0944. The authors wish to thank W. W. Stoffels and E. Stoffels for valuable discussion.

${ }^{1}$ A. Bouchoule, A. Plain, L. Boufendi, J. Ph. Blondeau, and C. Laure, J. Appl. Phys. 70, 1991 (1991).

${ }^{2}$ L. Boufendi and A. Bouchoule, Plasma Sources Sci. Technol. 3, 263 (1994). 